\title{
Paeoniflorin induces G2/M cell cycle arrest and caspase-dependent apoptosis through the upregulation of Bcl-2 X-associated protein and downregulation of B-cell lymphoma 2 in human osteosarcoma cells
}

\author{
LI-BIN JIN*, JIAN ZHU*, CHENG-ZHEN LIANG, LI-JIANG TAO, BING LIU, \\ WEI YU, HAN HUI ZOU, JUN-JIE WANG and HUIMIN TAO \\ Department of Orthopedics, The Second Affiliated Hospital, School of Medicine, \\ Zhejiang University, Hangzhou, Zhejiang 310009, P.R. China
}

Received October 7, 2016; Accepted June 27, 2017

DOI: $10.3892 / \mathrm{mmr} .2018 .8464$

\begin{abstract}
Paeoniflorin (PF), extracted from the peony root, has been proved to possess antineoplastic activity in different cancer cell lines. However, it remains unclear whether PF has an antineoplastic effect against osteosarcoma cells. The present study investigated the effects and the specific mechanism of PF on various human osteosarcoma cell lines. Using the multiple methods to detect the activity of PF on HOS and Saos-2 human osteosarcoma cell lines, including an MTS assay, flow cytometry, transmission electron microscopy and western blotting, it was demonstrated that PF induces inhibition of proliferation, G2/M phase cell cycle arrest and apoptosis in the osteosarcoma cell lines in vitro, and activation of cleaved-caspase-3 and cleaved-poly (ADPribose) polymerase in a dose-dependent manner. Furthermore, the pro-apoptotic factors Bcl-2 X-associated protein and BH3 interacting domain death agonist were uregulated, while the anti-apoptotic factors B-cell lymphoma 2 (Bcl-2) and Bcl-2-extra large were downregulated. In conclusion, these results demonstrated that $\mathrm{PF}$ has a promising therapeutic potential in for osteosarcoma.
\end{abstract}

\section{Introduction}

Osteosarcoma (OS), the most common primary malignant tumor of bone, has two age-specific peaks in incidence in

Correspondence to: Dr Huimin Tao, Department of Orthopedics, The Second Affiliated Hospital, School of Medicine, Zhejiang University, 88 Jie Fang Road, Hangzhou, Zhejiang 310009, P.R. China

E-mail: 2187040@zju.edu.cn

${ }^{*}$ Contributed equally

Key words: paeoniflorin, apoptosis, caspase, B-cell lymphoma 2 family, osteosarcoma children, adolescents ( $0-24$ years old) and the elderly ( $\geq 60$ years old) (1-3). The incidence rate of OS is $\sim 5-10$ million/year worldwide (4). With the combination of surgery and neoadjuvant chemotherapy treatment from 1980, patients with osteosarcoma have an improved survival time. However, the metastases or recurrence of the 5-year overall survival rate for OS patients is $20 \%$, which contributes to the majority of mortalities, while $65 \%$ of patients have localized disease (5). Additionally, the reduced effectiveness of cytotoxic drugs due to acquired chemoresistance is growing (6). Therefore, finding novel therapeutic agents is important to improve the prognosis.

Traditional Chinese medicines (7) have been used as a promising agent to treat osteosarcoma in patients with metastasis, chemoresistance and recurrence. Paeoniflorin $(\mathrm{PF})$ is isolated from the peony root. Previous research have demonstrated the proliferation inhibition and apoptosis induction by $\mathrm{PF}$ in many different tumor cells including hepatoma (8-10), cervical $(11,12)$, gastric (13-15), colorectal (16) and lung (17) cancers.

However, it remains to be determined whether PF has a treatment effect on osteosarcoma. Therefore, the present study investigated the anti-tumor effect of PF and the specific mechanism on human osteosarcoma cells. Since PF could inhibit proliferation and induce apoptosis in multiple neoplasias (18-20), it is highly possible that PF has the capacity to suppress proliferation and mediate apoptosis in human osteosarcoma cells. Additionally, cell cycle proteins, caspase protein and the B-cell lymphoma 2 (Bcl-2) family were investigated in relation to the effect of $\mathrm{PF}$ on osteosarcoma.

\section{Materials and methods}

Reagents and antibodies. PF was from Sigma-Aldrich; Merck KGaA (Darmstadt, Germany), with a purity $>98 \%$. The molecular formula of $\mathrm{PF}$ is $\mathrm{C}_{23} \mathrm{H}_{28} \mathrm{O}_{11}$, and its molecular weight is 480.46 . PF was dissolved in PBS to produce a stock solution. The PF stock solution was diluted in a cell culture 
medium prior to its use in each experiment. Trypsin $(0.25 \%)$, PBS, fetal bovine serum (FBS), Eagle's Minimum Essential medium (EMEM) and Mcroy' 5A medium were purchased from Gibco; Thermo Fisher Scientific, Inc. (Waltham, MA, USA). Hoechst 33258 and an MTS kit were from Promega Corporation (Madison, WI, USA). Antibodies against caspase-3 (cat. no. 9662), cleaved-caspase-3 (cat. no. 9661), poly (ADPribose) polymerase (PARP; cat. no. 9532), cleaved-PARP (cat. no. 5625), BH3 interacting domain death agonist (Bid; cat. no. 2002), Bcl-2 (cat. no. 4223), Bcl-2 X-associated protein (Bax; cat. no. 5023), Bcl-extra large (XL; cat. no. 2764), cyclin B1 (cat. no. 4135), p21 (cat. no. 2947) and $\beta$-actin (cat. no. 3700) were from Cell Signaling Technology, Inc., (Beverly, MA, USA). Antibodies against cyclin-dependent kinase (CDK)1 (cat. no. ab133327) and phosphorylated (p)-CDK1 (p-Y15; cat. no. ab133463) were purchased from Abcam (Cambridge, UK).

Cells and cell culture. The HOS [CRL-1547TM, American Type Culture Collection, Manassas, VA, USA (ATCC)] and Saos-2 (HTB-85TM; ATCC) human osteosarcoma cell lines were from the Cell Bank of Shanghai Institute of Biochemistry and Cell Biology, Chinese Academy of Sciences (Shanghai, China). HOS cells were cultured in EMEM and Saos-2 cells were cultured in Mcroy' 5A medium containing $10 \% \mathrm{FBS}$, penicillin $(100 \mathrm{U} / \mathrm{ml})$ and streptomycin $(100 \mu \mathrm{g} / \mathrm{ml}$; Sigma-Aldrich, Merck KGaA, Darmstadt, Germany). All cell lines were cultured at $37^{\circ} \mathrm{C}$ in a $5 \%$ (v/v) $\mathrm{CO}_{2}$ humidified incubator. The present study was approved by the Ethics Committee of the Second Affiliated Hospital of Zhejiang University Medical School (Zhejiang, China).

Cell viability assay. The viability of osteosarcoma cells treated with PF was measured by an MTS assay. In brief, cells were seeded into 96-well plates (5,000-6,000 cells/well) overnight, then they were treated with $\mathrm{PF}$ at concentrations ranging from 200 to $500 \mu \mathrm{M}$ for $0-48 \mathrm{~h}$. The MTS kit was added and cells were incubated at $37^{\circ} \mathrm{C}$ in a humidified incubator for $1-3 \mathrm{~h}$ following the manufacturer's protocol. Absorbance was read on a MR7000 microplate reader (Dynatech Nevada, Inc., Carson City, NV, USA) at $490 \mathrm{~nm}$ and the probit model was used to obtain IC50 values. Data were averaged in six replicates. Each assay was tested in triplicate.

Hoechst staining. To assess the characteristic morphological changes of osteosarcoma cell apoptosis, Hoechst 33258 staining followed by fluorescent microscopy was performed. Cells were treated with PF for $24 \mathrm{~h}$. Subsequently, cells were stained with Hoechst 33258 at room temperature for $10 \mathrm{~min}$. Subsequently, cells were washed twice with PBS and observed under a fluorescence microscope (Olympus Corporation, Tokyo, Japan) to identify chromatin condensation and nuclei fragmentation.

Morphological apoptosis. The morphological ultra-structure changes of treated and control cells were observed using transmission electron microscopy (TEM). Cells were fixed with $2.5 \%$ glutaraldehyde at $4^{\circ} \mathrm{C}$ for $4 \mathrm{~h}$ and post-fixed in $1 \%$ osmium tetroxide at $4^{\circ} \mathrm{C}$ for $1 \mathrm{~h}$. The cell pellets were embedded in epoxy resin following dehydration in different concentrations of alcohol. Sections $(0.5-\mu \mathrm{m})$ were treated with uranyl acetate and lead citrate, then observed at a magnification of $x 8,300$ under a transmission electron microscope.

Apoptosis proportion analysis. Apoptosis caused by PF was detected by Annexin V-fluorescein isothiocyanate (FITC)/propidium iodide (PI) staining (Biouniquer Technology, Nanjing, China). In brief, cells were incubated in six-well plates at a density of $2 \times 10^{5}$ cells/well and treated with varying concentrations of $\mathrm{PF}(0-500 \mu \mathrm{M})$ for $24 \mathrm{~h}$. The cells were stained using Annexin V-FITC (5 $\mu \mathrm{l})$ and PI $(5 \mu \mathrm{l})$ for $15 \mathrm{~min}$ in the dark. A flow cytometer (FACSCalibur; BD Biosciences, San Jose, CA, USA) and ModFit LT (version 3.3; Verity Software House, Topshame, ME, USA) was used to analyze the samples.

Cell cycle analysis. PI/RNase staining buffer (BD Biosciences) was used to determine cell cycle with flow cytometry. In brief, after incubation with different concentrations of PF ( 0 , 200,300 and $500 \mu \mathrm{M}$ ) for $24 \mathrm{~h}, \sim 5 \times 10^{5}$ cells were fixed with $70 \%$ ethanol at $-20^{\circ} \mathrm{C}$ for $24 \mathrm{~h}$. Following this, the cells were incubated with PI/RNase and tested with a flow cytometer (FACSCalibur).

Western blot analysis. Cells $\left(5 \times 10^{5}\right)$ were incubated in 60-mm dishes and treated with PF for $24 \mathrm{~h}$. Protein lysates were obtained by lysing cells with radioimmunoprecipitation assay lysis buffer (Sigma-Aldrich; Merck KGaA) containing a mixture of protease inhibitors (Sigma-Aldrich; Merck KGaA) for $0.5 \mathrm{~h}$ at $4^{\circ} \mathrm{C}$ to extract total proteins. Next, a bicinchoninic acid total protein quantitation kit was used to identify the protein content. Total proteins $(60 \mu \mathrm{g})$ were separated by electrophoresis on a 5\% stacking gel and an $8-12 \%$ separating gel. Proteins were transferred onto a polyvinylidene difluoride membrane (EMD Millipore, Billerica, MA, USA) and blocked with $5 \%$ bovine serum albumin at $20^{\circ} \mathrm{C}$ for $1 \mathrm{~h}$. Membranes were incubated with primary antibodies $(1: 1,000)$ at $4^{\circ} \mathrm{C}$ for $12 \mathrm{~h}$. After that, the membranes were washed five times with TBS with $0.1 \%$ Tween 20 and then incubated with goat anti-rabbit and anti-mouse immunoglobulin $\mathrm{G}$ horseradish peroxide conjugated secondary antibodies (Pierce; Thermo Fisher Scientific, Inc.; $1: 5,000)$ at $37^{\circ} \mathrm{C}$ for $1 \mathrm{~h}$. Following this, an Enhanced Chemiluminescence kit was used to visualize proteins with exposure to X-ray film (Kodak, Rochester, NY, USA). BandScan 5.0 software (Glyko, Inc., Novato, CA, USA) were used to analyze the density of strips. The relative expression amount of the target protein is expressed as: (Objective protein optical density value) $/(\beta$-actin optical density value) x10.

Statistical analysis. All data are expressed as the mean \pm standard deviation. The experiments were triplicated to obtain the mean values. The statistical differences were calculated by unpaired Student's t-test or one-way analysis of variance followed by Dunnett's test using SPSS software (version 17.0; SPSS, Inc., Chicago, IL, USA). $\mathrm{P}<0.05$ was considered to indicate a statistically significant difference. 
A

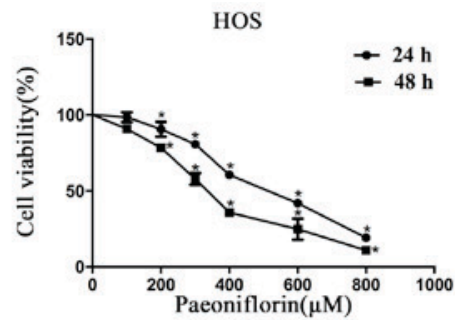

B
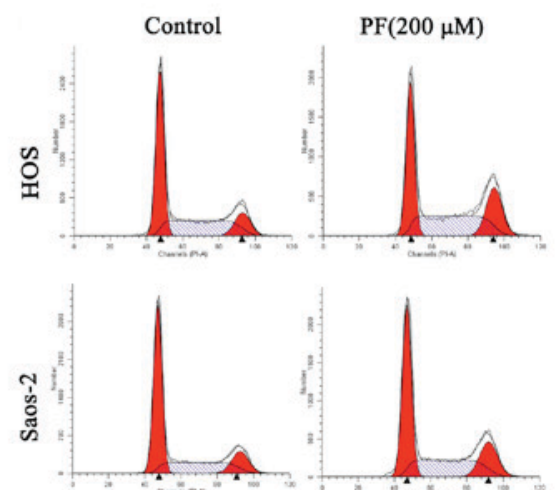

C

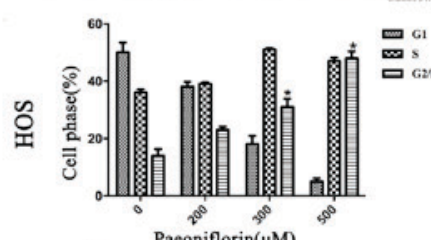
$\square^{61}$
$\mathbf{m}^{629}$

D
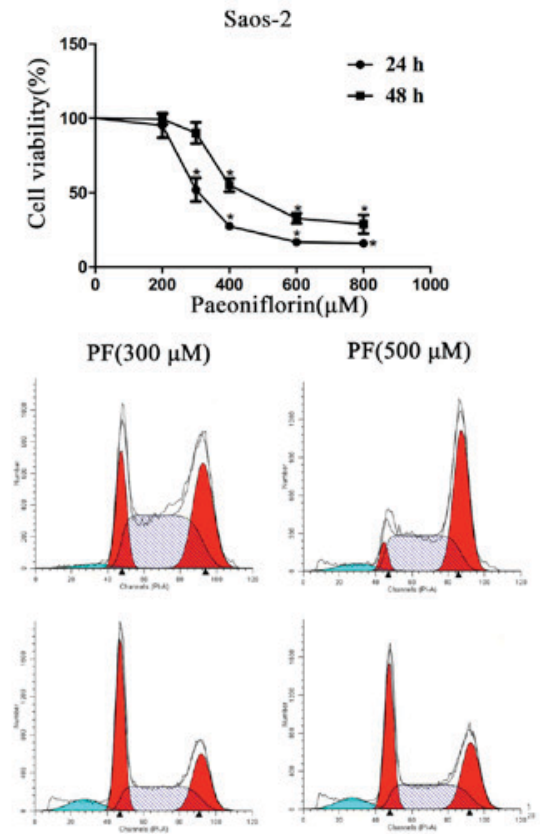

HOS

Saos-2

Ctrl $200 \quad 300 \quad 500$

$\mathrm{PF}(\mu \mathrm{M}) \quad \mathrm{Ctrl} 200300 \quad 500$

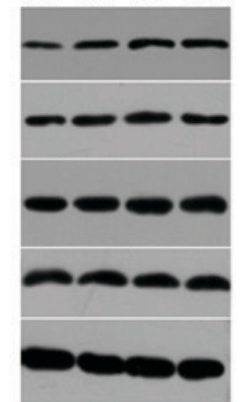

E

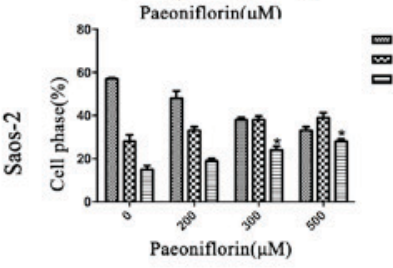

$\min ^{\mathrm{G} 1}$
$\cos ^{\mathrm{s}}$

p-CDK1

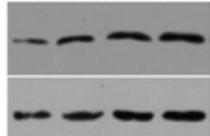

CDK1

CyclinB1

$\beta$-actin

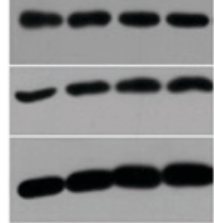

HOS
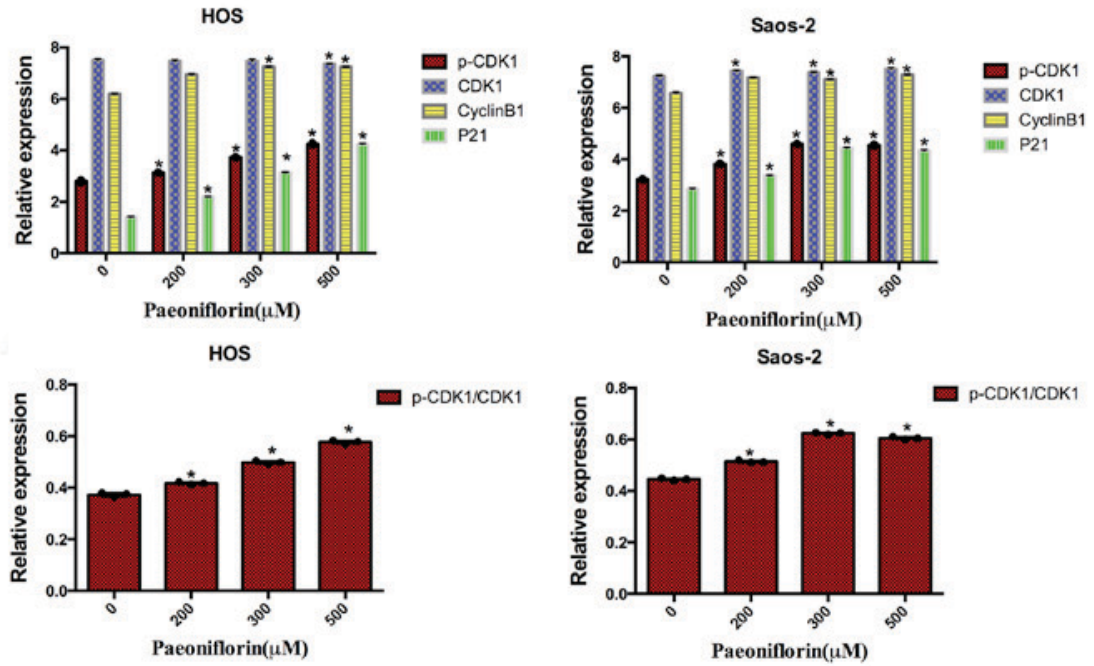

Figure 1. PF inhibits the cell viability of HOS and Saos-2 human osteosarcoma cells and induces cell cycle arrest. (A) MTS was used to test the effect of PF. (B) PF induces G2/M phase cell arrest, as analyzed by the flow cytometry. (C) The percentage of cells in each stage of the cell cycle. (D) Representative western blot images and (E) quantification of expression levels of the cell cycle-associated proteins p21, p-CDK1, CDK1 and cyclin B1. $\beta$-actin served as a loading control. Data are presented as the mean \pm standard deviation. ${ }^{*} \mathrm{P}<0.05$ vs. control $(0 \mu \mathrm{M})$. $\mathrm{PF}$, paeoniflorin; p, phosphorylated; CDK1, cyclin-dependent kinase 1 .

\section{Results}

PF inhibits cell viability in osteosarcoma cells in a doseand time-dependent manner. To study the effects of PF on the growth of osteosarcoma cells, an MTS assay was used to measure the cell viability of HOS and Saos-2 cells. As the concentration of PF increased, cell viability decreased; following incubation with PF for $48 \mathrm{~h}$, the IC50 values of PF 
A

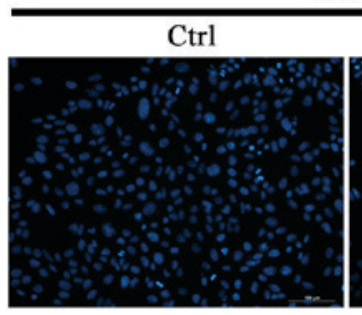

B
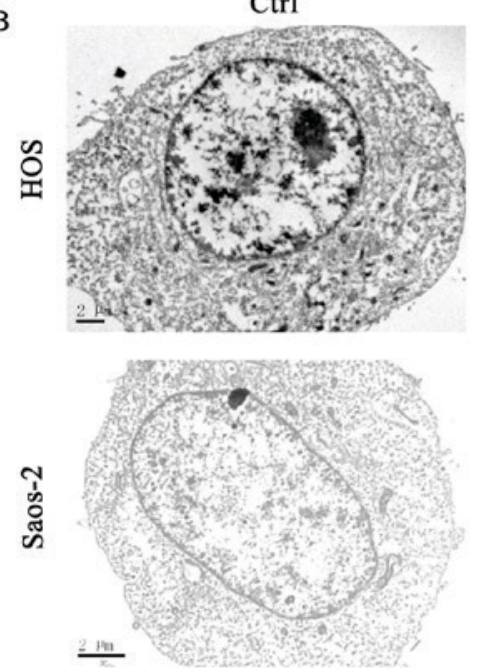

$\mathrm{PF}(300 \mu \mathrm{M})$

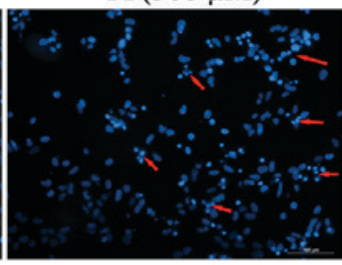

Saos-2

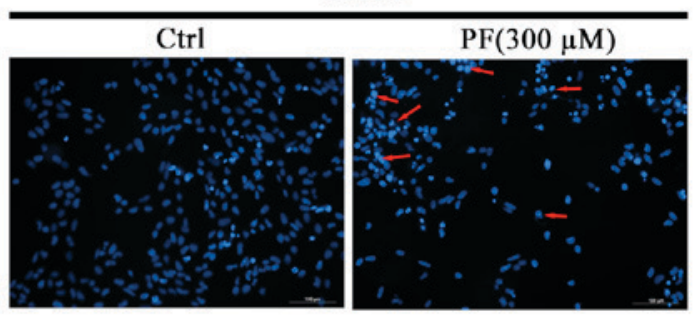

D
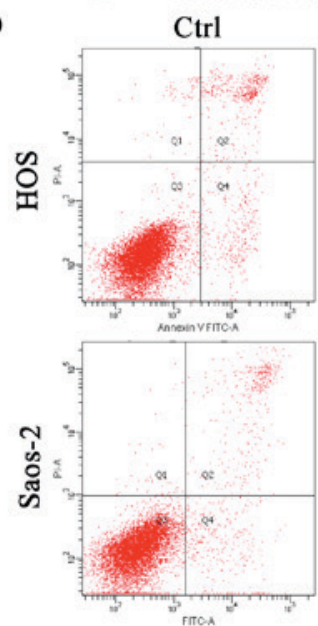

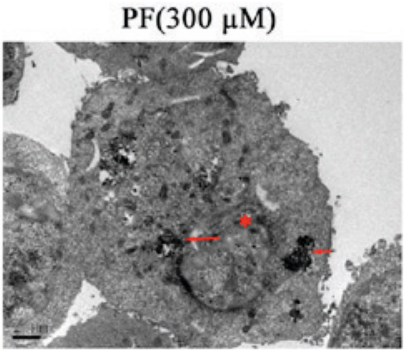

C
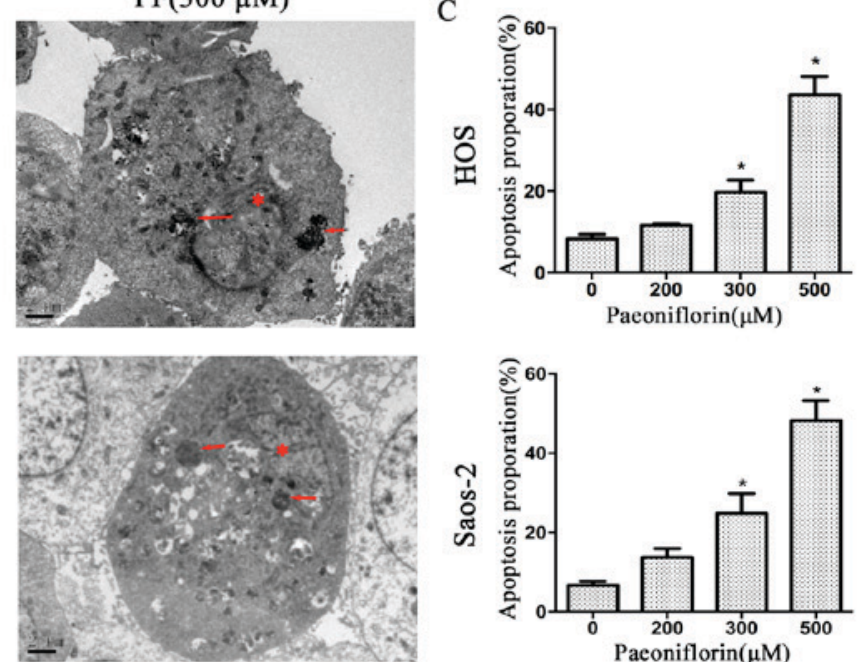

$\mathrm{PF}(200 \mu \mathrm{M})$
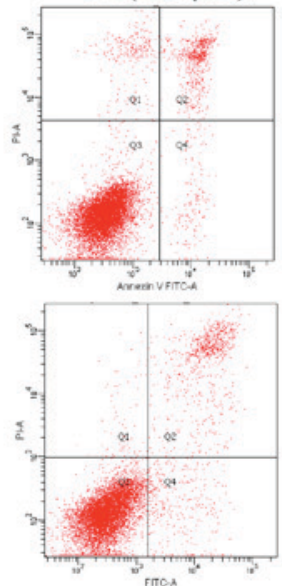

$\operatorname{PF}(300 \mu \mathrm{M})$
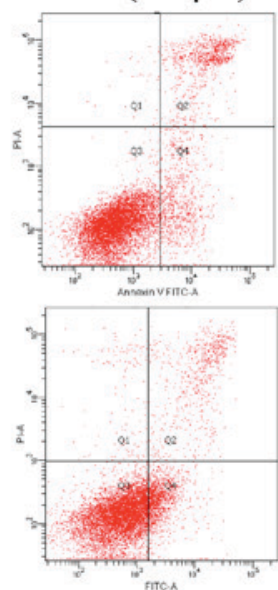

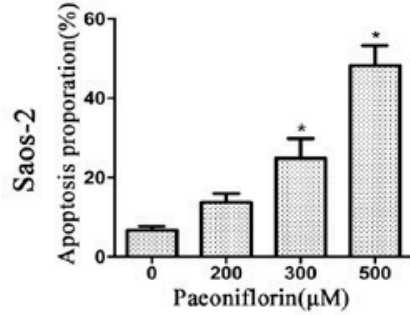

$\mathrm{PF}(500 \mu \mathrm{M})$
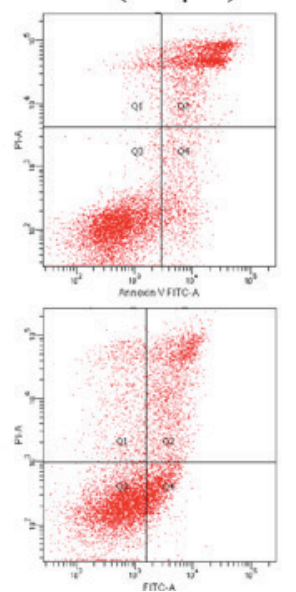

Figure 2. PF induces cell apoptosis in HOS and Saos-2 human osteosarcoma cells. (A) Hoechst 33258 staining was used to detect the apoptotic morphological changes and stain the nuclei. Arrows indicate chromatin condensation and DNA fragmentation. Scale bar=100 $\mu \mathrm{m}$. (B) The ultrastructure of apoptotic cells was detected with a transmission electron microscope (magnification, x8,300). Cell shrinkage, a denser cytoplasm, cytoplasmic vacuoles, nuclear condensation and the presence of apoptotic bodies were observed in both HOS and Saos-2 cells treated with PF. Arrows indicate nuclear condensation and asterisks indicate disruption of nuclear membrane. Scale bar=2 $\mu \mathrm{m}$. (C) Histograms and (D) flow cytometry graphs of Annexin V/PI staining. Data are presented as the mean \pm standard deviation of three independent experiments. ${ }^{*} \mathrm{P}<0.05$ vs. control $(0 \mu \mathrm{M})$. Ctrl, control; PF, paeoniflorin; PI, propidium iodide; FITC, fluorescein isothiocyanate.

were $363.29 \mu \mathrm{M}$ for HOS and $351.24 \mu \mathrm{M}$ for Saos-2 (Fig. 1A). The results indicated that PF has the capability to inhibit cell viability in a dose- and time-dependent manner.

PF induces cell cycle arrest at the G2/M phase and regulates cell cycle protein expression levels in osteosarcoma. In order to demonstrate whether PF inhibits cell proliferation through mediating cell cycle arrest, flow cytometry analyses were used to examine the distribution of the cell cycle. As presented in Fig. 1B and C, after incubating with PF for $48 \mathrm{~h}, \mathrm{HOS}$ and Saos-2 cells exhibited a significant increase in G2/M phase arrest, with a corresponding decline in the $\mathrm{G} 0 / \mathrm{G} 1$ and $\mathrm{S}$ phases in a dose-dependent manner. To determine the underlying mechanism, the protein expression levels of cyclin B1, CDK1, p-CDK1 and p21, which have been demonstrated to be cell cycle-regulating proteins, were assessed. The protein expression levels of cyclin B1,p-CDK1,CDK1 and p21 increased after treating with PF in HOS and Saos-2 cells in a dose-dependent manner (Fig. 1D and E).

PF induces apoptosis in human osteosarcoma cell lines. To investigate the inhibition mechanism of PF in the proliferation 


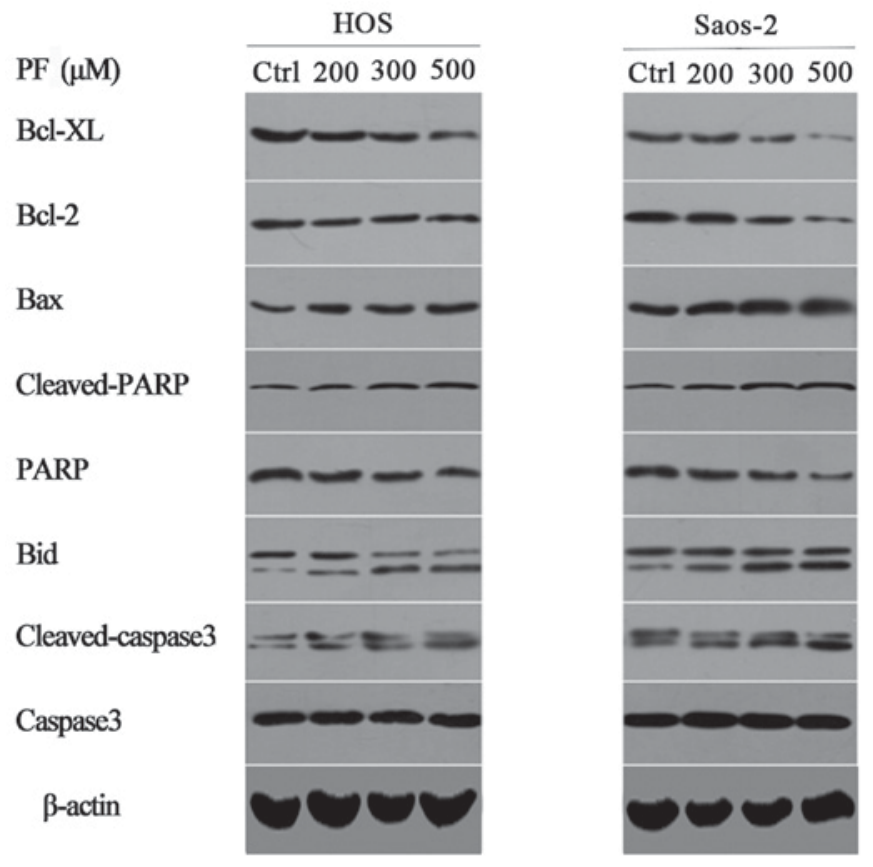

Figure 3. Representative western blot images of cleaved caspase-3, caspase-3, cleaved PARP, PARP and the Bcl-2 family of proteins, including Bid, Bax, Bcl-2 and Bcl-XL in human osteosarcoma cells treated with PF for $24 \mathrm{~h}$. $\beta$-actin served as a loading control. PF, paeoniflorin; Bcl-2, B-cell lymphoma 2; XL, extra large; Bax, Bcl-2 X-associated protein; PARP, poly (ADPribose) polymerase; Bid, BH3 interacting domain death agonist; Ctrl, control.

A
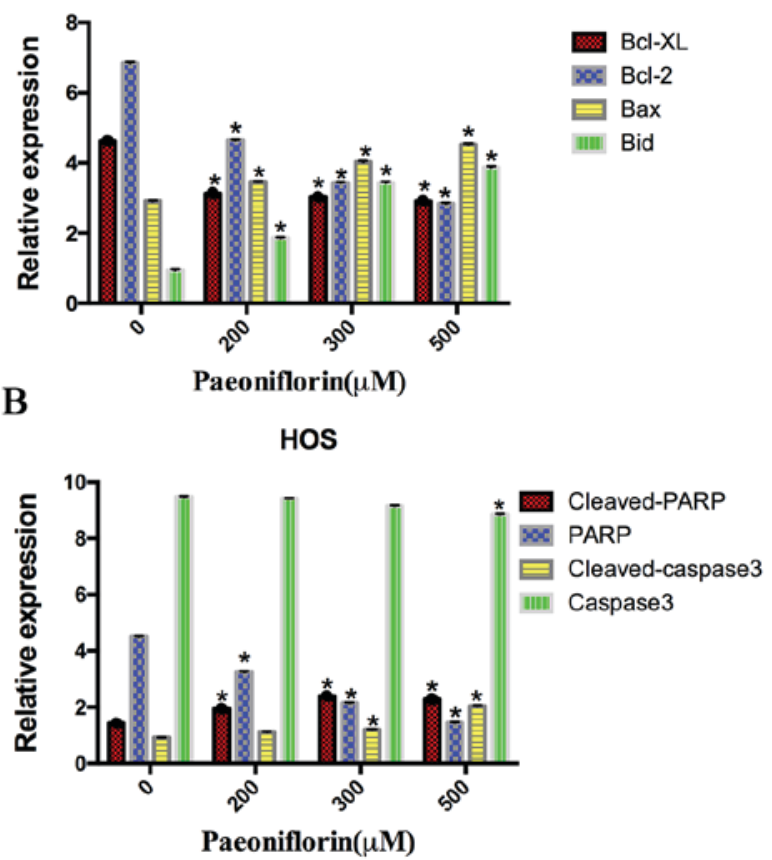

Saos-2

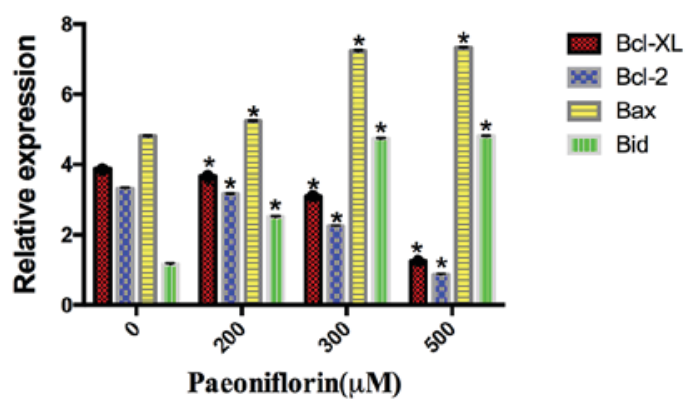

Saos-2

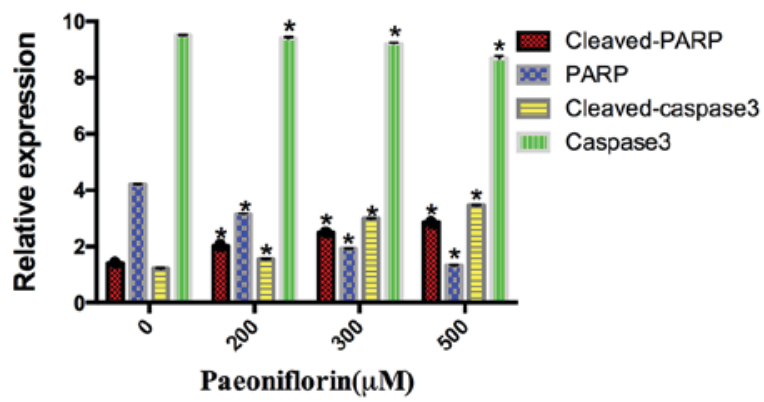

Figure 4. Quantification of protein expression levels of apoptosis-associated proteins following paeoniflorin treatment in (A and B) HOS and Saos-2 human osteosarcoma cells. The relative expression amount of the target protein is expressed as: (Objective protein optical density value)/( $\beta$-actin optical density value) $\mathrm{x} 10$. Data are presented as the mean \pm standard deviation. ${ }^{*} \mathrm{P}<0.05$ vs. control $(0 \mu \mathrm{M})$. Bcl-2, B-cell lymphoma 2 ; XL, extra large; Bax, Bcl-2 X-associated protein; PARP, poly (ADPribose) polymerase; Bid, BH3 interacting domain death agonist.

of osteosarcoma cells, Hoechst 33258, TEM and flow cytometry analyses were used in the present study. The Hoechst 33258 staining revealed morphological changes when the cells were treated with $\mathrm{PF}$, such as karyopyknosis and nuclear fragmentation (Fig. 2A). Furthermore, TEM revealed more detailed apoptotic morphological features in cells treated with
PF compared with control cells, including cell shrinkage, a denser cytoplasm, cytoplasmic vacuoles, karyopyknosis and the presence of apoptotic bodies (Fig. 2B). Next, flow cytometry analysis was used to quantify PF-induced apoptosis in human osteosarcoma cells. PF led to apoptosis in osteosarcoma cell lines in a dose-dependent manner, consistent with 
the results of the MTS assay. Following treatment with PF, Saos-2 cells exhibited increased rates of apoptosis from $6.3 \%$ at $0 \mu \mathrm{M}$ to $48.7 \%$ at $500 \mu \mathrm{M}$, and HOS cells from $8.8 \%$ at $0 \mu \mathrm{M}$ to $43.8 \%$ at $500 \mu \mathrm{M}$ (Fig. $2 \mathrm{C}$ and D). The result was consistent with the finding demonstrated by the MTS assay.

PF induces the apoptosis in the human osteosarcoma cells by regulating the expression of $\mathrm{Bcl}-2, \mathrm{Bcl}-\mathrm{XL}, \mathrm{Bax}, \mathrm{Bid}, \mathrm{PARP}$ and caspase-3 in osteosarcoma cells. To detect the potential cell signaling pathways in apoptosis induced by $\mathrm{PF}$, the protein expression levels of the caspase-3, PARP and Bcl-2 family were examined (Fig. 3). The expression levels of Bcl-2 and Bcl-XL protein were downregulated following PF treatment in a dose-dependent manner, in both cell lines. However, the levels of Bax and Bid protein were upregulated after incubation with $\mathrm{PF}$ for $48 \mathrm{~h}(\mathrm{P}<0.05)$. Additionally, the levels of cleaved caspase-3 and cleaved PARP protein were significantly upregulated in a dose-dependent manner $(\mathrm{P}<0.05)$. Therefore, these results demonstrated that apoptosis induced by PF occurred via downregulation of the anti-apoptotic proteins Bcl-XL and Bcl-2 and upregulation of the pro-apoptotic proteins Bax, Bid, PARP and caspase-3 (Fig. 4).

\section{Discussion}

There is increasing evidence indicating the anti-tumor properties of PF in multiple cancer cells, but the impact of PF on human osteosarcoma cells remains to be determined. In this study, it was indicated that PF inhibited the proliferation of osteosarcoma cells in a dose- and time-dependent manner.

To elucidate the mechanisms underlying the anticancer properties of PF, further studies were further conducted. Annexin V-FITC/PI double staining illustrated that PF causes $\mathrm{G} 2 / \mathrm{M}$ phase cell cycle arrest and apoptosis in a dose-dependent manner within a 0-500 $\mu \mathrm{M}$ range. Fluorescence and electron microscopy revealed morphological changes following PF treatment, such as cell shrinkage, a denser cytoplasm, cytoplasmic vacuoles, karyopyknosis and the presence apoptotic bodies. The present study illustrated in vitro that PF has a therapeutic effect on osteosarcoma through $\mathrm{G} 2 / \mathrm{M}$ phase cell cycle arrest and inducing apoptosis.

Consistent with previous reports, the present study demonstrated that the cell cycle G2 checkpoint (21) is also a target of PF. The cyclin B1/CDK1 complex is an important regulators of $\mathrm{G} 2 / \mathrm{M}$ cell arrest (22-24). p21 was demonstrated to serve a role in regulating $\mathrm{G} 2$ phase cell cycle progression through the p53-dependent or p53-independent signaling pathways $(25,26)$. As HOS and Saos-2 cells are p53-mutant, p53-independent factors serve a central role in the upregulation of $\mathrm{p} 21$.

Caspases, a cysteine protease family, act as an important regulator of apoptosis. Once the cell is in the process of apoptosis, the stimuli will trigger a caspase signaling cascade (27). Caspase-3 marks the end of the downstream effect of caspases $(28,29)$, the primary executioner of programmed cell death. PARP is the substrate of caspase-3 (30), a key regulator of apoptosis. In the present study, the dose of PF upregulated the cleavage of caspase- 3 and cleaved-PARP and simultaneously inhibited the protein expression levels of procaspase-3 and PARP, while increasing the rate of apoptosis. These findings illustrated that PF inhibits osteosarcoma cells by activating apoptotic pathways.

To further illuminate the specific molecular mechanisms, related upstream apoptotic proteins were investigated. Llambi et al (31) reported that mitochondria-mediated apoptosis is mainly associated with the Bcl-2 family. The Bcl-2 family can be separated into two categories: One involving anti-apoptotic proteins including Bcl-2 and Bcl-XL, the other involving is pro-apoptotic proteins, mainly including Bax and Bid (32). Bid is a proapoptotic BH3-only member of the Bcl-2 family, and when cleaved into the truncated Bid, it will translocate to the mitochondria to cause apoptosis $(33,34)$, which is also called mitochondrial outer membrane permeabilization (MOMP), the final common pathway of apoptosis $(35,36)$. Bax forms the MOMP pore, while Bcl-2 and Bcl- XL, the anti-apoptotic proteins, locate in the outer wall of mitochondria and inhibit its formation $(37,38)$. Therefore, in the pathway of apoptosis, the ratio of $\mathrm{Bax} / \mathrm{Bcl}-2$ and $\mathrm{Bax} / \mathrm{Bcl}-\mathrm{XL}$ serve an important role, in addition to the expression levels of Bcl-2 family members (39). The results indicated that PF suppresses HOS and Saos-2 cells proliferation in vitro through the mitochondrial signaling pathway.

In conclusion, although the specific mechanism of PF in osteosarcoma has not been totally identified, these dataindicated that PF may induce apoptosis of osteosarcoma cells directly or indirectly through the mediation of apoptosis, resulting in $\mathrm{G} 2 / \mathrm{M}$ cell cycle arrest, indicating a potential therapeutic agent for osteosarcoma. However, further in vivo studies are required to further elucidate these mechanisms.

\section{Acknowledgements}

The present study was supported by the National Natural Science Foundation of China (grant no. 81472504), the National Natural Science Foundation of China (grant no. 81401822) and the Science and Technology Planning Project of Zhejiang Province (grant no. 2013C33231).

\section{References}

1. Knops RR, van Dalen EC, Mulder RL, Leclercq E, Knijnenburg SL, Kaspers GJ, Pieters R, Caron HN and Kremer LC: The volume effect in paediatric oncology: A systematic review. Ann Oncol 24: 1749-1753, 2013.

2. Rainusso N, Wang LL and Yustein JT: The adolescent and young adult with cancer: State of the art-bone tumors. Curr Oncol Rep 15: 296-307, 2013.

3. Mirabello L, Troisi RJ and Savage SA: International osteosarcoma incidence patterns in children and adolescents, middle ages and elderly persons. Int J Cancer 125: 229-234, 2009.

4. Kuijjer ML, Hogendoorn PC and Cleton-Jansen AM: Genome-wide analyses on high-grade osteosarcoma: Making sense of a genomically most unstable tumor. Int J Cancer 133: 2512-2521, 2013.

5. Isakoff MS, Bielack SS, Meltzer P and Gorlick R: Osteosarcoma: Current treatment and a collaborative pathway to success. J Clin Oncol 33: 3029-3035, 2015.

6. Shen C, Wang W, Tao L, Liu B, Yang Z and Tao H: Chloroquine blocks the autophagic process in cisplatin-resistant osteosarcoma cells by regulating the expression of p62/SQSTM1. Int J Mol Med 32: 448-456, 2013.

7. Liang CZ, Zhang X, Li H, Tao YQ, Tao LJ, Yang ZR, Zhou XP, Shi ZL and Tao HM: Gallic acid induces the apoptosis of human osteosarcoma cells in vitro and in vivo via the regulation of mitogen-activated protein kinase pathways. Cancer Biother Radiopharm 27: 701-710, 2012. 
8. Gong WG, Lin JL, Niu QX, Wang HM, Zhou YC, Chen SY and Liang GW: Paeoniflorin diminishes ConA-induced IL-8 production in primary human hepatic sinusoidal endothelial cells in the involvement of ERK1/2 and Akt phosphorylation. Int J Biochem Cell Biol 62: 93-100, 2015.

9. Hu S, Sun W, Wei W, Wang D, Jin J, Wu J, Chen J, Wu H and Wang Q: Involvement of the prostaglandin E receptor EP2 in paeoniflorin-induced human hepatoma cell apoptosis. Anticancer Drugs 24: 140-149, 2013.

10. Lu JT, He W, Song SS and Wei W: Paeoniflorin inhibited the tumor invasion and metastasis in human hepatocellular carcinoma cells. Bratisl Lek Listy 115: 427-433, 2014

11. Zhang L and Zhang S: Modulating Bcl-2 family proteins and caspase-3 in induction of apoptosis by paeoniflorin in human cervical cancer cells. Phytother Res 25: 1551-1557, 2011.

12. Zhang LL, Zhang SL and Wang SZ: Relevant study on apoptosis of cervical cancer HeLa cells induced by paeoniflorin. Zhonghua Yi Xue Za Zhi 90: 3371-3375, 2010 (In Chinese).

13. Fang S, Zhu W, Zhang Y, Shu Y and Liu P: Paeoniflorin modulates multidrug resistance of a human gastric cancer cell line via the inhibition of NF- $\mathrm{KB}$ activation. Mol Med Rep 5: 351-356, 2012.

14. Zheng YB, Xiao GC, Tong SL, Ding Y, Wang QS, Li SB and Hao ZN: Paeoniflorin inhibits human gastric carcinoma cell proliferation through up-regulation of microRNA-124 and suppression of PI3K/Akt and STAT3 signaling. World J Gastroenterol 21: 7197-7207, 2015.

15. Wu H, Li W, Wang T, Shu Y and Liu P: Paeoniflorin suppress NF-kappaB activation through modulation of I kappaB alpha and enhances 5-fluorouracil-induced apoptosis in human gastric carcinoma cells. Biomed Pharmacother 62: 659-666, 2008 .

16. Wang H, Zhou H, Wang CX, Li YS, Xie HY, Luo JD and Zhou Y: Paeoniflorin inhibits growth of human colorectal carcinoma HT 29 cells in vitro and in vivo. Food Chem Toxicol 50: 1560-1567, 2012.

17. Hung JY, Yang CJ, Tsai YM, Huang HW and Huang MS Antiproliferative activity of paeoniflorin is through cell cycle arrest and the Fas/Fas ligand-mediated apoptotic pathway in human non-small cell lung cancer A549 cells. Clin Exp Pharmacol Physiol 35: 141-147, 2008.

18. Wang S and Liu W: Paeoniflorin inhibits proliferation and promotes apoptosis of multiple myeloma cells via its effects on microRNA29b and matrix metalloproteinase2. Mol Med Rep 14: 2143-2149, 2016

19. Wu Q, Chen GL, Li YJ, Chen Y and Lin FZ: Paeoniflorin inhibits macrophage-mediated lung cancer metastasis. Chin J Nat Med 13: 925-932, 2015

20. Nie XH, Ou-yang J, Xing Y, Li DY, Dong XY, Liu RE and Xu RX: Paeoniflorin inhibits human glioma cells via STAT3 degradation by the ubiquitin-proteasome pathway. Drug Des Devel Ther 9: 5611-5622, 2015

21. Vairapandi M, Balliet AG, Hoffman B and Liebermann DA GADD45b and GADD45g are cdc2/cyclinB1 kinase inhibitors with a role in $\mathrm{S}$ and $\mathrm{G} 2 / \mathrm{M}$ cell cycle checkpoints induced by genotoxic stress. J Cell Physiol 192: 327-338, 2002.

22. Li M, Stefansson B, Wang W, Schaefer EM and Brautigan DL: Phosphorylation of the Pro-X-Thr-Pro site in phosphatase inhibitor-2 by cyclin-dependent protein kinase during M-phase of the cell cycle. Cell Signal 18: 1318-1326, 2006.

23. Sabour Alaoui S, Dessirier V, de Araujo E, Alexaki VI, Pelekanou V, Lkhider M, Stathopoulos EN, Castanas E, Bagot M, Bensussan A and Tsapis A: TWEAK affects keratinocyte G2/M growth arrest and induces apoptosis through the translocation of the AIF protein to the nucleus. PloS One 7: e33609, 2012.
24. Zhao Y, Khanal P, Savage P, She YM, Cyr TD and Yang X: YAP-induced resistance of cancer cells to antitubulin drugs is modulated by a Hippo-independent pathway. Cancer Res 74 4493-4503, 2014

25. Dalvai M, Mondesert O, Bourdon JC, Ducommun B and Dozier C: Cdc25B is negatively regulated by p53 through Sp1 and NF-Y transcription factors. Oncogene 30: 2282-2288, 2011.

26. Zhang W, Liu Y, Zhao N, Chen H, Qiao L, Zhao W and Chen JJ: Role of Cdk1 in the p53-independent abrogation of the postmitotic checkpoint by human papillomavirus E6. J Virol 89: 2553-2562, 2015.

27. Liang CZ, Zhang JK, Shi ZL, Liu B, Shen CQ and Tao HM: Matrine induces caspase-dependent apoptosis in human osteosarcoma cells in vitro and in vivo through the upregulation of Bax and Fas/FasL and downregulation of Bcl-2. Cancer Chemother Pharmacol 69: 317-331, 2012.

28. Tao LJ, Zhou XD, Shen CC, Liang CZ, Liu B, Tao Y and Tao HM: Tetrandrine induces apoptosis and triggers a caspase cascade in U2-OS and MG-63 cells through the intrinsic and extrinsic pathways. Mol Med Rep 9: 345-349, 2014.

29. Yang SJ, Lee SA, Park MG, Kim JS, Yu SK, Kim CS, Kim JS, Kim SG, Oh JS, Kim HJ, et al: Induction of apoptosis by diphenyldifluoroketone in osteogenic sarcoma cells is associated with activation of caspases. Oncol Rep 31: 2286-2292, 2014.

30. Sairanen T, Szepesi R, Karjalainen-Lindsberg ML, Saksi J, Paetau A and Lindsberg PJ: Neuronal caspase-3 and PARP-1 correlate differentially with apoptosis and necrosis in ischemic human stroke. Acta Neuropathol 118: 541-552, 2009

31. Llambi F, Moldoveanu T, Tait SW, Bouchier-Hayes L, Temirov J, McCormick LL, Dillon CP and Green DR: A unified model of mammalian BCL-2 protein family interactions at the mitochondria. Mol Cell 44: 517-531, 2011.

32. Kvansakul M and Hinds MG: The Bcl-2 family: Structures, interactions and targets for drug discovery. Apoptosis 20: 136-150, 2015

33. Grohm J, Plesnila $\mathrm{N}$ and Culmsee C: Bid mediates fission, membrane permeabilization and peri-nuclear accumulation of mitochondria as a prerequisite for oxidative neuronal cell death Brain Behav Immun 24: 831-838, 2010.

34. Yuan XJ and Whang YE: PTEN sensitizes prostate cancer cells to death receptor-mediated and drug-induced apoptosis through a FADD-dependent pathway. Oncogene 21: 319-327, 2002

35. Green DR and Kroemer G: The pathophysiology of mitochondrial cell death. Science 305: 626-629, 2004.

36. Suh DH, Kim MK, Kim HS, Chung HH and Song YS Mitochondrial permeability transition pore as a selective target for anti-cancer therapy. Front Oncol 3: 41, 2013.

37. Jonas EA, Porter GA Jr, Beutner G, Mnatsakanyan $\mathrm{N}$ and Alavian KN: Cell death disguised: The mitochondrial permeability transition pore as the c-subunit of the $\mathrm{F}(1) \mathrm{F}(\mathrm{O})$ ATP synthase. Pharmacol Res 99: 382-392, 2015.

38. Pang X, Moussa SH, Targy NM, Bose JL, George NM, Gries C, Lopez H, Zhang L, Bayles KW, Young R and Luo X: Active Bax and Bak are functional holins. Genes Dev 25: 2278-2290, 2011.

39. Lindenboim L, Ferrando-May E, Borner C and Stein R Non-canonical function of Bax in stress-induced nuclear protein redistribution. Cell Mol Life Sci 70: 3013-3027, 2013.

This work is licensed under a Creative Commons Attribution-NonCommercial-NoDerivatives 4.0 International (CC BY-NC-ND 4.0) License. 